\title{
Diagnosis and minimally invasive treatment of chronic discogenic low back paín
}

Citation for published version (APA):

Kallewaard, J. W. (2019). Diagnosis and minimally invasive treatment of chronic discogenic low back pain. [Doctoral Thesis, Maastricht University]. Maastricht University. https://doi.org/10.26481/dis.20191106jk

Document status and date:

Published: 01/01/2000

DOI:

10.26481/dis.20191106jk

Document Version:

Publisher's PDF, also known as Version of record

\section{Please check the document version of this publication:}

- A submitted manuscript is the version of the article upon submission and before peer-review. There can be important differences between the submitted version and the official published version of record.

People interested in the research are advised to contact the author for the final version of the publication, or visit the DOI to the publisher's website.

- The final author version and the galley proof are versions of the publication after peer review.

- The final published version features the final layout of the paper including the volume, issue and page numbers.

Link to publication

\footnotetext{
General rights rights.

- You may freely distribute the URL identifying the publication in the public portal. please follow below link for the End User Agreement:

www.umlib.nl/taverne-license

Take down policy

If you believe that this document breaches copyright please contact us at:

repository@maastrichtuniversity.nl

providing details and we will investigate your claim.
}

Copyright and moral rights for the publications made accessible in the public portal are retained by the authors and/or other copyright owners and it is a condition of accessing publications that users recognise and abide by the legal requirements associated with these

- Users may download and print one copy of any publication from the public portal for the purpose of private study or research.

- You may not further distribute the material or use it for any profit-making activity or commercial gain

If the publication is distributed under the terms of Article $25 \mathrm{fa}$ of the Dutch Copyright Act, indicated by the "Taverne" license above, 
This thesis aims to define the diagnostic algorithm for chronic discogenic low back pain (CD-LBP) and to assess the evidence for minimally invasive treatments for CD-LBP, including the reproduction of a randomized controlled trial on the effect of intradiscal methylene blue injection on CD-LBP.

\section{Background}

Low back pain is a major and growing problem worldwide. The Global Burden of Diseases, Injuries and Risk factor study (2017') showed that low back pain is the number one cause of years lived with disability. This burden poses considerable challenges to health systems and economies. 2,3

Low back pain has a multifactorial origin. In approximately $40 \%$ of the cases, LBP appears to be of discogenic origin. ${ }^{4,5}$ The sacroiliac (SI) joint or the facet joints are indicated as the cause of LBP in $13 \%$ and $15-40 \%$ of the cases, respectively. In clinical practice often more than one cause can be found simultaneously. ${ }^{5}$

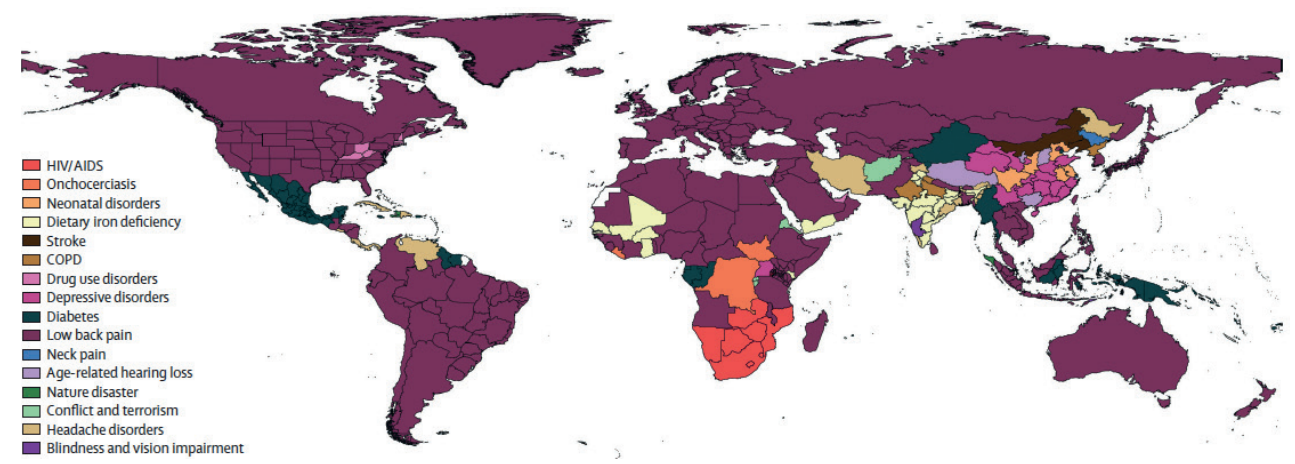

Figure 1: Importance of low back pain as leading cause of age-standardized years lived with disability rated by location, for both sexes combined, 2017. From Global Burden of Disease ${ }^{1}$ free of copyright.

Discogenic low back pain, although attributed to a degenerative process, may improve spontaneously over time. For patients presenting with discogenic low back pain conservative management, consisting of medication and a multidisciplinary rehabilitation program that focusses on reducing pain and provides instructions on posture and body movement, is recommended first.

The World Health Organization (WHO) uses a stepwise approach to the pharmacological treatment of pain. ${ }^{6}$ The last decades reports on the increasing number of opioid deaths 
and addiction, especially in the population of non-cancer pain sufferers, justify a critical assessment of the advantages and disadvantages of long-term opioid use. Recent guidelines on the treatment of low back pain discourage to use opioids for managing chronic low back pain. ${ }^{7}$ The development of anti-neuropathic medication added another dimension to the treatment algorithm dividing pain into mechanical pain, neuropathic pain or combined pain syndromes.

The selection of a minimally invasive treatment option can only be made when the pain source is identified. In patients with chronic mechanical low back pain, the facet and sacroiliac joints as pain generators should first be excluded, before the intervertebral disc can be suspected as a pain generator. ${ }^{8}$ Disc degeneration and pathologies can best be visualized with Magnetic Resonance Imaging (MRI) in T1 and T2 setting. ${ }^{9}$ Desiccation, loss of height, high-intensity zones ( $\mathrm{HIZ}$ ) and Modic signs can be visualized. However, radiologic findings correlate poorly with the clinical presentation. It is well known that asymptomatic discs may appear abnormal on MRI, while normal appearing discs have been shown to be painful on provocation. ${ }^{10}$

The inconsistency of history, physical examination, and radiographic findings leaves the critical question: "How can the diagnosis of discogenic low back pain be made?"

Provocative discography may provide the link in diagnosing suspected discs as the origin of low back pain. The answer is a technique that combines imaging, intradiscal pressure, and pain reproduction, together with morphologic abnormalities observed on MRI. This test can be indicative of the discogenic origin of low back pain. ${ }^{11}$ Discography is an invasive procedure and long term follow up of discography patients has demonstrated acceleration of disc degeneration. ${ }^{12}$ It was demonstrated in degenerative porcine discs that pressure transfer to the adjacent disc happens during discography. ${ }^{13}$

Although it has yet to be demonstrated that any targeted intervention can reliably treat discs, identified as the anatomic source of pain by provocative discography, it is argued that there is a place for discography as a diagnostic utility. ${ }^{14,15}$

A good diagnostic test offers the patient a source for their pain, the best patient selection for the treatment of CD-LBP and possibly the best treatment results.

The answers found for the research questions formulated for this thesis, aim at improving diagnosis and selection of the most appropriate minimally invasive treatment strategy for patients with CD-LBP. 


\section{Research question1:}

What is the current evidence for minimally invasive treatments in discogenic low back pain: A systematic review of the literature?

Chapter 2 a summarizes the literature relative to the diagnosis and treatment of discogenic pain up till $2010 .^{8}$

In Chapter $\mathbf{2 b}$ we present the update of the evidence for the interventional pain management options based on the literature up to March 2018. This review showed evidence of moderate quality for intradiscal biacuplasty, resulting in a moderate strength of recommendation for its use in a highly selected patient group with CD-LBP. The randomized controlled study on the effect of intradiscal methylene blue injection was judged to be of moderate quality: its criticisms and the lack of reproduction of the results, justified a weak recommendation. Intradiscal electrothermal therapy was supported by evidence of low quality.

\section{Research question 2:}

Is the pressure transfer to an adjacent disc in disc stimulation real and significant? Recently, an in vivo porcine study and a study in nine human subjects showed pressure transfer to the adjacent discs during discography. This could mean that the concordant pain the patient describes originates from an adjacent disc. ${ }^{13,16}$

In chapter 3 we describe a cohort of patients in which during provocative discography pressure was measured in adjacent discs. ${ }^{17}$

Fifty patients were selected with suspected CD-LBP. An arterial blood pressure monitoring system simultaneously assessed the pressure in the adjacent discs while low-speed flow, pressure-controlled discography was performed on the suspected discs.

In patients with a positive discography, the average intradiscal peak pressure was $15.1 \mathrm{psi}$ (SD-11.1). In 48 procedures, no pressure rise in the adjacent discs was found. A small, but not clinically relevant rise (1.1 psi) in the adjacent disc during discography was recorded in 2 patients.

The pressure rise in adjacent discs does not seem to occur during low-speed flow pressurecontrolled provocation discography in human discs. False-positive pain reaction caused by potentially painful adjacent discs are therefore unlikely during low-speed flow (low) pressure-controlled discography. 


\section{Research question 3:}

What is the place of intradiscal methylene blue injection in patients with CD-LBP?

In chapter $\mathbf{4}$ we describe the results of a prospective case-cohort study of the intradiscal injection of methylene blue in CD-LBP. ${ }^{18}$

Patients were carefully selected on clinical criteria, magnetic resonance imaging, and a positive provocative discography.

Copying the protocol of Peng et al., ${ }^{19} 15$ consecutive patients, were injected with $1 \mathrm{ml}$ of methylene blue $10 \%, 1 \mathrm{ml}$ lidocaine $1 \%$ and $0.5 \mathrm{ml}$ of contrast dye.

Patients were recruited in two interventional pain treatment centers of the Netherlands. Six months after the intervention, $40 \%$ of the patients claimed at least $30 \%$ pain relief. In patients who responded, physical function improved, and medication use diminished. These patients were defined as responders. We observed no complications or adverse events.

These findings justified the set up of a randomized, double-blind, placebo-controlled trial.

In chapter 5 we describe the results of the multicenter randomized controlled trial on the efficacy of intradiscal methylene blue (MB) injection for CD-LBP: the Intradiscal Methylene Blue Injection (IMBI) study. ${ }^{20}$

In this RCT, the design of the previously published study by Peng et al. ${ }^{19}$ was replicated. A multicenter RCT was performed to assess whether the extraordinary effect of intradiscal $\mathrm{MB}$ on pain intensity could be confirmed. Success was defined as at least a $30 \%$ reduction, in pain intensity and the Patients' Global Impression of Change (PGIC) 6 months after the intervention. To include 84 patients, we screened 1364 patients. Patients were excluded from participation because of successful test block of the facet joints $(n=191)$, suffering from a pain syndrome different from CD-LBP $(n=409)$, not fulfilling other inclusion and exclusion criteria $(n=177)$, refusing to participate in the study $(n=248)$, negative discography $(n=155)$ and other reasons $(n=100)$.

Although we exactly replicated the study protocol by Peng et al. ${ }^{19}$ we were unable to reproduce their effect size. We included 84 patients with CD-LBP of which $14(35 \%)$ in the $M B$ + lidocaine group showed treatment success compared with $11(26,8 \%)$ in the control group who received isotonic saline plus lidocaine $(\mathrm{P}=0.43)$. Twenty-seven percent of all participants treated with $\mathrm{MB}$ stated that their overall health improved much or very much vs $26 \%$ in the control group ( $P=0.96)$. 
We were unable to confirm that intradiscal $M B$ injections reduced pain significantly in patients with CD-LBP 6 months after treatment compared with placebo. As a remarkable finding, we observed that over one-quarter of patients receiving only lidocaine injections reported treatment success, which is in contrast with the previously published study.

We recommend further research to study the exact mechanisms of CD-LBP and to define specific characteristics of subgroups of patients with CD-LBP to determine whether intradiscal injections (with MB or lidocaine 1\%) may be a treatment option.

At present we do not recommend the routine use of intradiscal MB for CD-LBP.

\section{Research question 4:}

Is there a place for spinal cord or DRG stimulation in patients with CD-LBP?

Failed Back Surgery Syndrome (FBSS) is defined as a surgical end stage after one or more interventions on the (lumbar) spine, without persisting effect.

Spine surgeons do not describe this situation anymore as FBSS but "persisting or recurrent pain" after spine surgery.

A systematic review of the literature ${ }^{21}$ and an $\mathrm{RCT}^{22}$ demonstrated that spinal cord stimulation (SCS) is effective for the treatment of FBSS. An RCT compared SCS with reoperation. ${ }^{23}$ Patients selected as candidates for reoperation after spine surgery were randomly assigned to reoperation or SCS. If the results of the randomized treatment were unsatisfactory, patients could cross over to the alternative treatment. SCS was more effective than reoperation and fewer patients initially treated with SCS crossed over to surgery than vice versa.

Recently a special electrode allowing to stimulate the dorsal root ganglion (DRG) became available. Stimulation of the DRG is thought to produce targeted stimulation and optimal paresthesia coverage of the painful area compared with SCS. ${ }^{24}$ The innervation of the discs is provided by the sinu-vertebral nerves and the rami communicantes, which are sympathetic nerves. The sinu-vertebral nerve is implicated in diffuse low back pain. It cannot directly reach the somatic element of each level of the lumbar spine. ${ }^{25}$ The cutaneous innervation from L3 to L5 must therefore, pass through the nearest somatic nervous system structure, which is the spinal ganglion L2. (see figure 2) Therefore, the bilateral DRG L2 is considered a target for interventional pain treatment. 

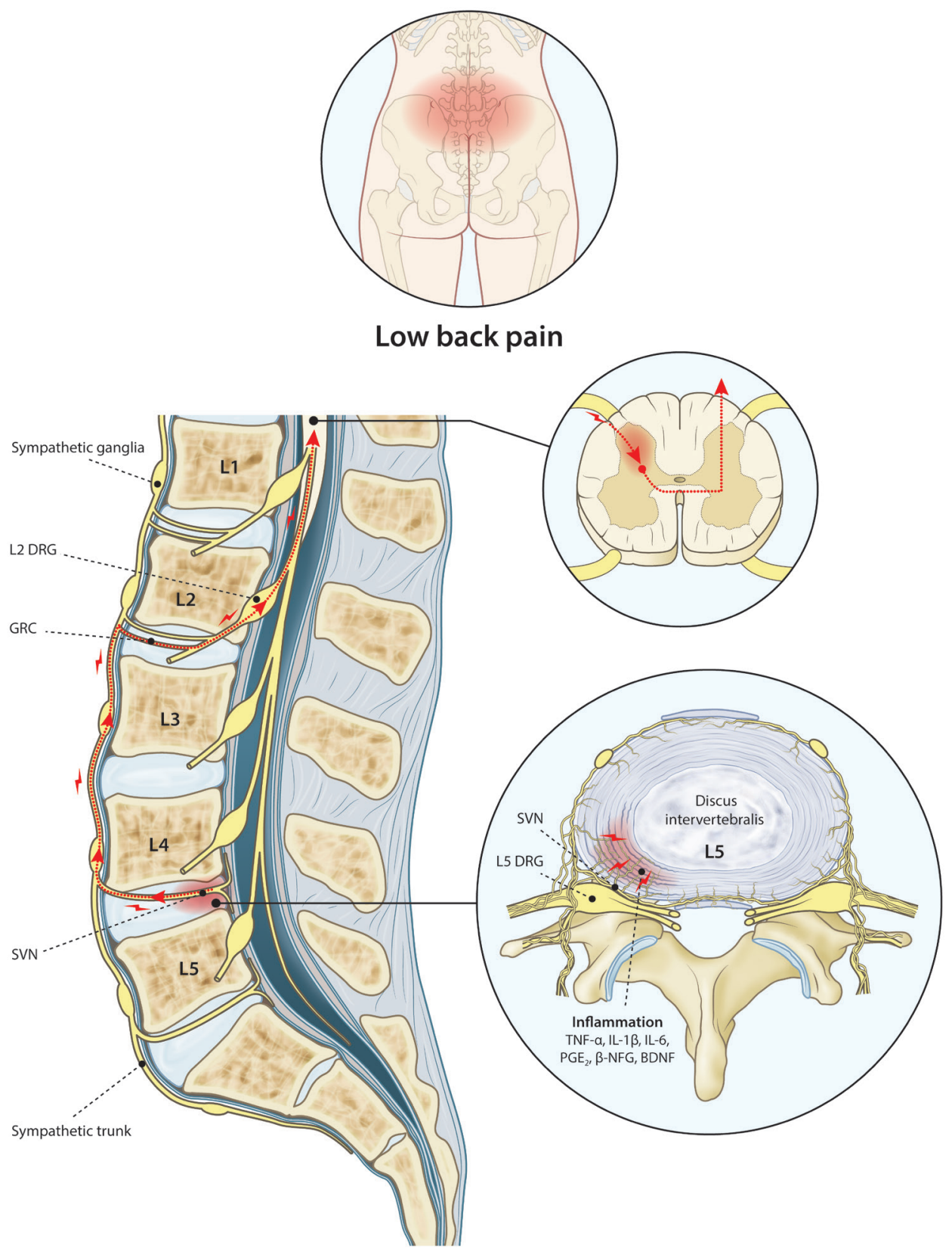

Figure 2: Innervation of the discus intervertebralis.

Rogier Trompert Medical Art. http://www.medical-art.eu.

In chapter 6, we describe the results of DRG stimulation in a group of patients with FBSS. We found that DRG L2 stimulation improves low back pain, function, and quality of life of FBSS patients. ${ }^{26}$ 
This study is a multi-center single arm observational cohort study of patients with persisting back and leg pain after lumbar spine surgery. Patients failed conservative and minimally invasive treatments.

Thirteen patients underwent a trial of DRG stimulation. Good paresthesia coverage of the painful area in the low back region was typically achieved with $L 2$ stimulation, the majority of the DRG leads for leg pain were placed at L4-L5 level to cover chronic neuropathic leg pain. Eleven patients had good results and underwent implantation of a permanent neurostimulator. The pain was reduced from $8.64( \pm 0.92)$ at baseline to $2.40( \pm 2.38 n=9)$ after 12 -months of treatment, a $72.05 \%$ reduction. Similar improvements were observed looking at secondary clinical outcome measures.

These results suggest that DRG stimulation induces pain relief in patients diagnosed with FBSS.

An interesting finding was the substantial effect of DRG L2 stimulation on chronic neuropathic low back pain.

In chapter 7, we describe a prospective pilot study (non-responders from the IMBI RCT after 24 months) who received DRG L2 stimulation ${ }^{27}$

This study was launched to investigate the utility of DRG stimulation at the L2 spinal level for patients with CD-LBP who had not undergone previous back surgery.

Twenty patients with confirmed discogenic pain, and no prior history of back surgery, underwent trials of DRG stimulation (bilateral DRG L2) and were permanently implanted when pain relief of at least $50 \%$ was achieved.

Treatment with DRG L2 stimulation for CD-LBP reduced LBP pain rating (68.3\% reduction), from mean $7.20 \pm 1.3$ at baseline to $2.29 \pm 2.1$ after 12 -months $(p=<0.001)$. Oswestry disability ratings significantly decreased from $42.09 \pm 12.9$ at baseline to $21.54 \pm 16.4$ after six months of treatment and to $20.1 \pm 16.6$ after 12-months of treatment. The average quality of life EQ-5D index score at baseline was $0.61 \pm 0.12$ and $0.84 \pm 0.13$ after 12 -months.

The outcomes of DRG stimulation in the treatment of CD-LBP are very promising but these are the first results in a small prospective study. These results should be reproduced in a large trial and compared to conventional spinal cord stimulation also looking at the cost-effectiveness and invasiveness of the procedure.

In every patient, a comparative assessment should be made of the invasiveness of a procedure against the health profit to be gained. 